\title{
C-Band Polarimetric Coherences and Ratios for Discriminating Sea Ice Roughness
}

\author{
Mukesh Gupta, Randall K. Scharien, and David G. Barber \\ Centre for Earth Observation Science, Department of Environment and Geography, Clayton H. Riddell Faculty of Environment, \\ Earth, and Resources, University of Manitoba, Winnipeg, MB, Canada R3T 2N2
}

Correspondence should be addressed to Mukesh Gupta; mukesh_gupta@umanitoba.ca

Received 10 December 2012; Revised 2 April 2013; Accepted 26 April 2013

Academic Editor: Grant Bigg

Copyright (C) 2013 Mukesh Gupta et al. This is an open access article distributed under the Creative Commons Attribution License, which permits unrestricted use, distribution, and reproduction in any medium, provided the original work is properly cited.

The rapid decline of sea ice in the Arctic has resulted in a variable sea ice roughness that necessitates improved methods for efficient observation using high-resolution spaceborne radar. The utility of C-band polarimetric backscatter, coherences, and ratios as a discriminator of ice surface roughness is evaluated. An existing one-dimensional backscatter model has been modified to twodimensions (2D) by considering deviation in the orientation (i.e., the slopes) in azimuth and range direction of surface roughness simultaneously as an improvement in the model. It is shown theoretically that the circular coherence $\left(\rho_{\text {RRLL }}\right)$ decreases exponentially with increasing surface roughness. The crosspolarized coherence $\left(\rho_{\mathrm{HHVH}}\right)$ is found to be less sensitive to surface roughness, whereas the copolarized coherence $\left(\rho_{\mathrm{VVHH}}\right)$ decreases at far-range incidence angles for all ice types. A complete validation of the adapted $2 \mathrm{D}$ model using direct measurements of surface roughness is suggested as an avenue for further research.

\section{Introduction}

Arctic sea ice is going through a rapid decline $[1,2]$. Thinner first-year ice (FYI) is replacing multiyear ice, leaving an ice cover, which is more sensitive to deformation and changes in atmospheric and ocean forcing. Increased open water and marginal ice zones (MIZs), due to the enhanced mobility of a relatively thinned pack ice, are further susceptible to increases in surface roughness and greater surface roughness variability [3]. Greater surface roughness in the MIZ is of importance due to higher rates of heat flux [4] and momentum [5] exchanges occurring across the ocean-sea iceatmosphere interface, greater biological productivity [6], and potential limitations imposed on ship navigation. Although the literature contains information on how the MIZ responds to wind and wave forces, it is necessary to investigate the electromagnetic (EM) response of the MIZ to facilitate satellitebased observations. Satellite-based observation is necessary due to the scarcity of surface observations in a MIZ, as well as the difficulties in collecting physical measurements due to the instability and roughness of the ice floes.

The use of polarimetric synthetic aperture radar (polSAR) represents a promising approach for satellite-based monitoring of surface roughness and, concurrently, discriminating sea ice types within a MIZ. A pol-SAR records the amplitude and phase information of backscattered energy for four transmit-receive polarizations $(\mathrm{HH}, \mathrm{HV}, \mathrm{VH}$, and VV), thereby facilitating the derivation of the full polarimetric response of the target. It is recognizable that the diversity in polarization achievable by pol-SARs or even by dualpolarization SAR systems provides more complete inference of target features (e.g., sea ice) than conventional, single channel SARs. Furthermore, recently launched pol-SARs are capable of higher spatial resolution $(<10 \mathrm{~m})$ imaging, leading to enhanced potential for monitoring complex ice environments.

Discrimination of ice types using SAR has been conventionally achieved by utilizing different combinations of linearly polarized backscattering coefficients [7-9]. Multiyear ice, smooth FYI, rough FYI, and new ice/open water in the Beaufort and Chukchi Seas during March have been identified using a single-polarization SAR image intensitybased classification scheme [9] while others used singlepolarization SAR image texture analysis to discriminate new ice, FYI, and multiyear ice during the month of March in the Beaufort Sea and the Mould Bay, respectively [10, 11]. Dual 


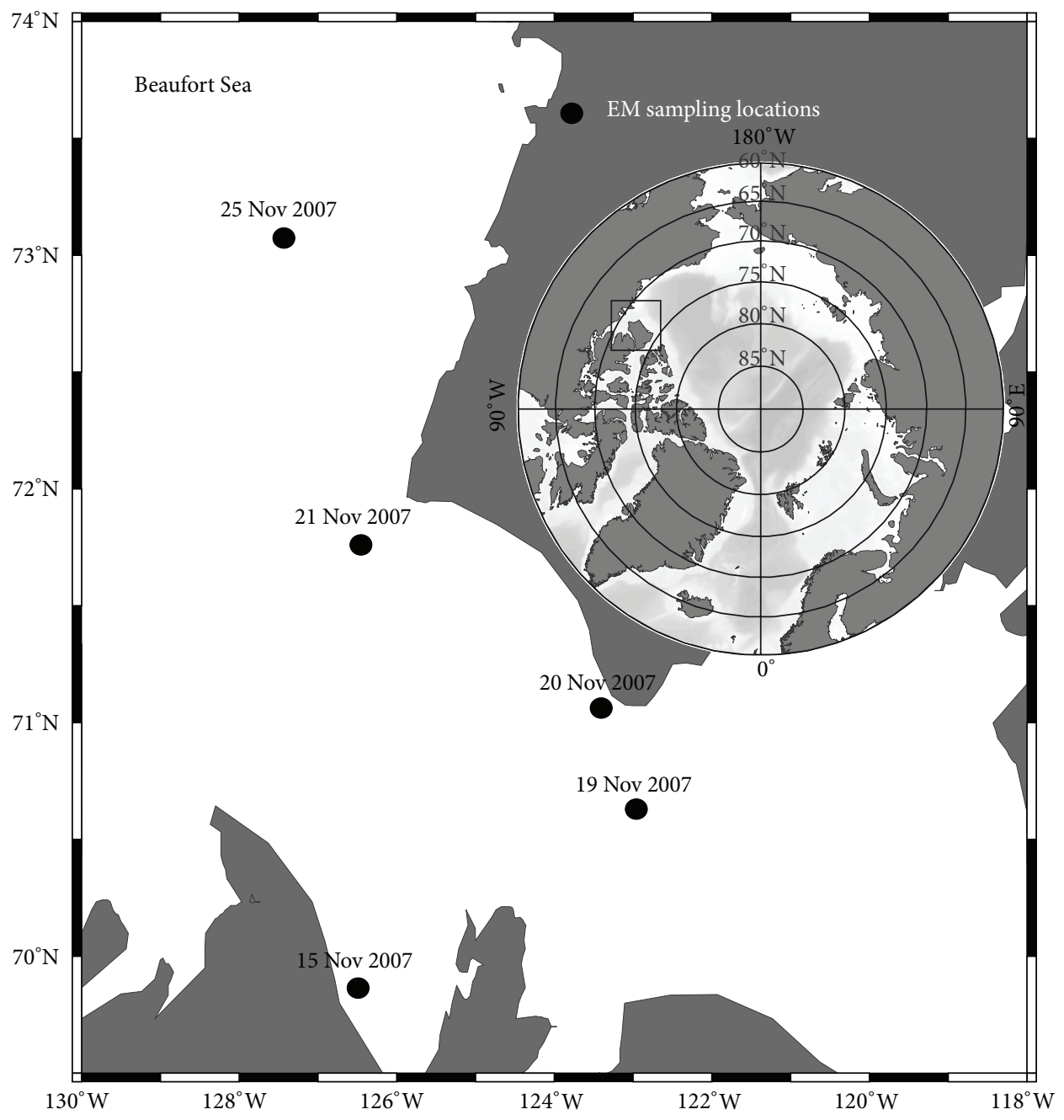

FIGURE 1: Geographic map of study area showing sampling locations.

copolarized backscattering coefficient differences in $\mathrm{HH}$ and VV have been used to discriminate FYI, multiyear ice, and lead areas in the Beaufort Sea during March [12]. However, the complexities in polarimetric signatures associated with the dynamic mixture of surface roughness and ice type conditions in an MIZ during fall freeze-up remain to be examined. Such an examination requires utilizing polarimetric radar backscatter, so that the material (dielectric) and geometrical properties of the surface, which influence backscatter, may be individually assessed.

In this study, ship-based observations of co- (linear) and crosspolarized backscatter, circular polarimetric coherences ( $\rho_{\mathrm{VVHH}}, \rho_{\mathrm{HHVH}}$, and $\rho_{\mathrm{RRLL}}$, resp.), and copolarized and crosspolarized polarization ratios $\left(\gamma_{\mathrm{co}}\right.$ and $\gamma_{\text {cross }}$, resp. $)$, are used to evaluate their utility for ice surface discrimination capabilities using a polarimetric radar operating in C-band $(5.5 \mathrm{GHz})$. Characteristics of these polarimetric parameters for a variety of ice types in an MIZ during fall freeze-up are assessed with the following objectives:

(1) to investigate the performance of polarimetric $\rho_{\text {RRLL }}$ for sea ice surface roughness discrimination by adapting the one-dimensional backscatter model of [13] to two dimensions and introducing roughness as deviations in range and azimuth directions,

(2) to evaluate the utility of C-band polarimetric backscatter, coherences, and polarization ratios as a discriminator of surface roughness or ice type in a MIZ during fall freeze-up.

\section{Methodology}

2.1. Study Area. The study area is located in the southeastern Beaufort Sea and Amundsen Gulf regions in the western Canadian Arctic (Figure 1). The seasonal Cape Bathurst Polynya forms in the region and hosts a number of flaw leads during the winter [14]. During fall freeze-up, this area contains a variable mix of ice types under various stages of formation, for example, new ice, pancake ice, frost flowers, deformed ice, gray ice, and nilas (Figure 2). The photographs in Figures 2(a), 2(b), 2(c), and 2(e) were taken at an oblique angle from the port side of the Canadian Research Icebreaker Amundsen at approximately eight meters height using a handheld digital camera after a given scatterometer scan; Figure 2(d) was taken at nadir angle on the ice floe 


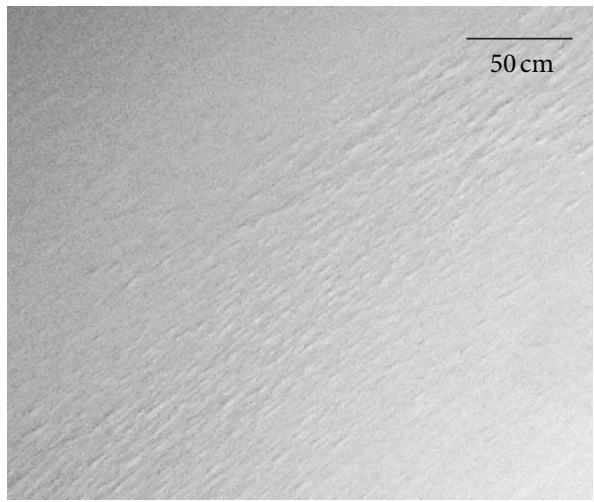

(a)

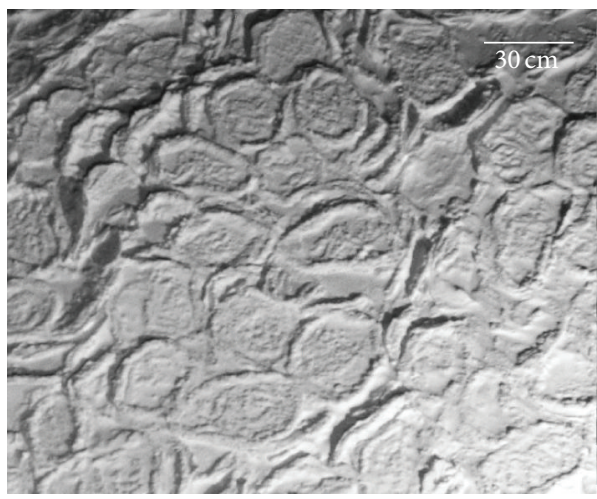

(c)

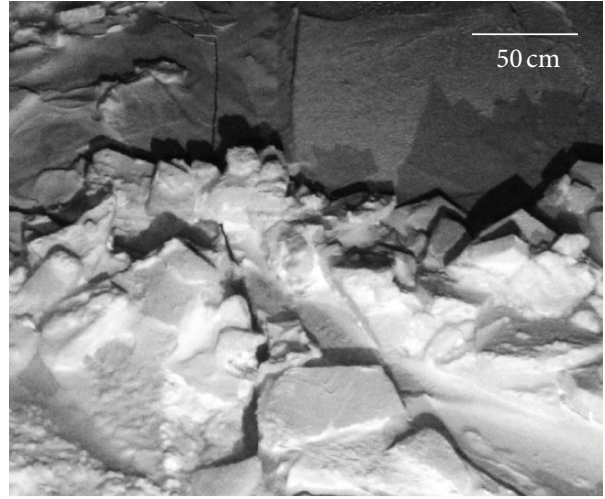

(b)

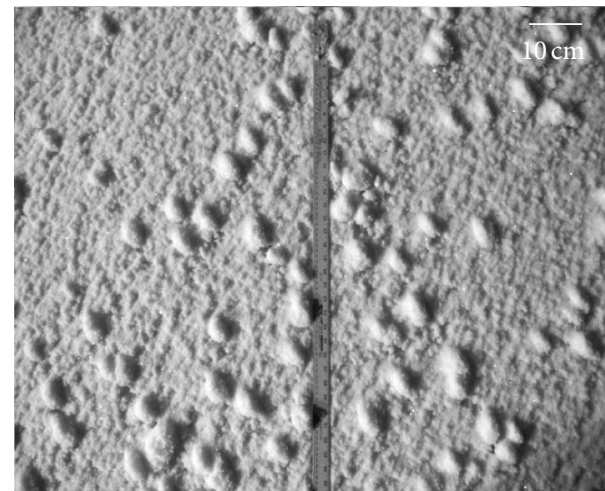

(d)

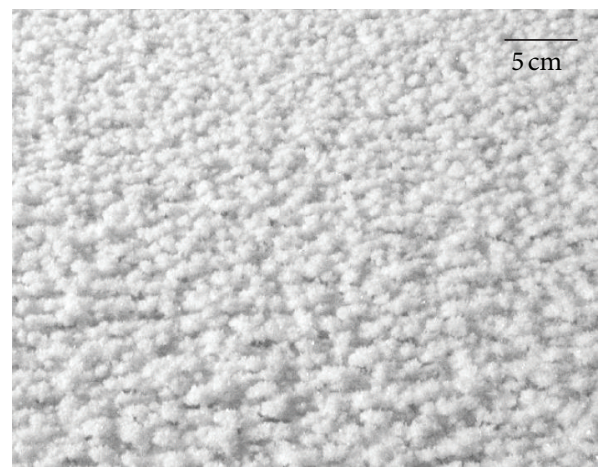

(e)

FIGURE 2: Photographs of ice types used in the study. (a) snow-covered first-year ice (SCFYI), (b) deformed first-year ice (DFYI), (c) consolidated pancake ice (PI), (d) snow-covered frost flower (SCFF), and (e) dense frost flower (DFF).

at about one meter height. In the present study, thin FYI types are considered (first stage: $30-50 \mathrm{~cm}$ - as per World Meteorological Organization nomenclature), which include snow-covered FYI, pancake ice, frost flowers, and deformed FYI located within the MIZ. Data described in the following sections were acquired as part of the Circumpolar Flaw Lead (CFL) System Study project of the International Polar Year (IPY) 2007-08 over the period October 2007-August 2008 [15]. Ancillary meteorological data were collected through a ship-based AXYS Technologies Inc. (Sydney, BC, Canada) Automatic Voluntary Observing Ships (AVOS) system. This system was mounted approximately $20 \mathrm{~m}$ above sea level on the wheelhouse to minimize the ship's influence and could measure air temperature and wind speed.
2.2. Theoretical Formulation. Sea ice is a distributed radar target, and the conditions of stationarity and homogeneity seldom hold for dynamically changing ice in a MIZ. The radar backscattering is therefore analyzed using temporally and spatially varying stochastic processes. Backscatter from sea ice is incoherent and either partially or completely polarized, as described by the polarimetric covariance matrix. The electric field vector of an incident (i) and scattered (s) EM wave can be given by

$$
\begin{aligned}
\mathbf{E}^{i} & =E_{H i} \widehat{\mathbf{h}}+E_{V i} \widehat{\mathbf{v}}, \\
\mathbf{E}^{s} & =E_{H s} \widehat{\mathbf{h}}+E_{V s} \widehat{\mathbf{v}},
\end{aligned}
$$


TABLE 1: Technical properties and specifications of C-band scatterometer.

\begin{tabular}{ll}
\hline RF output frequency & $5.25-5.75 \mathrm{GHz}$ \\
Transmit power at bulkhead connector & $12 \mathrm{dBm}$ \\
Antenna diameter & $0.61 \mathrm{~m}$ \\
Transmit bandwidth & $500 \mathrm{MHz}$ \\
Antenna beamwidth & $5.5^{\circ}$ \\
Antenna gain & $28 \mathrm{~dB}$, nominal \\
Crosspolarization isolation & $>30 \mathrm{~dB}$, measured at the peak of the beam \\
Transmit-receive polarizations & Linear, vertical, and horizontal \\
Sensitivity, minimum NRCS at $15 \mathrm{~m}$ range & $-40 \mathrm{~dB} \mathrm{~m}^{2} / \mathrm{m}^{2}$ \\
\hline
\end{tabular}

where $H$ and $V$ represent horizontal and vertical polarizations respectively. $\widehat{\mathbf{h}}$ and $\widehat{\mathbf{v}}$ are the unit vectors in the horizontal and vertical directions of polarization, respectively. The incident $(i)$ and scattered field $(s)$ can be either $H$ or $V$. The scattered electric field is related to the incident electric field by the scattering matrix, $S$ defined as

$$
\begin{aligned}
{\left[\begin{array}{c}
E_{H s} \\
E_{V s}
\end{array}\right]=} & \frac{e^{-j k r}}{r}\left[\begin{array}{ll}
S_{\mathrm{HH}} & S_{\mathrm{HV}} \\
S_{\mathrm{VH}} & S_{\mathrm{VV}}
\end{array}\right]\left[\begin{array}{c}
E_{H i} \\
E_{V i}
\end{array}\right], \\
& {\left[\begin{array}{ll}
S_{\mathrm{HH}} & S_{\mathrm{HV}} \\
S_{\mathrm{VH}} & S_{\mathrm{VV}}
\end{array}\right]=S, }
\end{aligned}
$$

where $e^{-j k r} / r$ term accounts for wave propagation effects in amplitude and phase. If the orientation of a surface such as sea ice in azimuth direction is rotated by an angle, the corresponding new backscatter matrix can be constructed as provided by Lee et al. [16].

The coherency matrices can be derived as copolarized (3), crosspolarized (4) and circular (RRLL: right-right left-left rotation of the electric field vector about the line of sight) (5) coherences in magnitude form $[13,16]$ as (for derivation of $\rho_{\text {RRLL }}$, see Appendix A),

$$
\begin{gathered}
\rho_{\mathrm{VVHH}}=\frac{\left\langle\left|S_{\mathrm{VV}} S_{\mathrm{HH}}^{*}\right|\right\rangle}{\sqrt{\left\langle\left|S_{\mathrm{VV}}\right|^{2}\right\rangle\left\langle\left|S_{\mathrm{HH}}\right|^{2}\right\rangle}}, \\
\rho_{\mathrm{HHVH}}=\frac{\left\langle\left|S_{\mathrm{HH}} S_{\mathrm{VH}}^{*}\right|\right\rangle}{\sqrt{\left\langle\left|S_{\mathrm{HH}}\right|^{2}\right\rangle\left\langle\left|S_{\mathrm{VH}}\right|^{2}\right\rangle}}, \\
\rho_{\mathrm{RRLL}}=\frac{\left\langle\left|S_{\mathrm{HH}}-S_{\mathrm{VV}}\right|^{2}\right\rangle-4\left\langle\left|S_{\mathrm{HV}}\right|^{2}\right\rangle}{\left\langle\left|S_{\mathrm{HH}}-S_{\mathrm{VV}}\right|^{2}\right\rangle+4\left\langle\left|S_{\mathrm{HV}}\right|^{2}\right\rangle}, \\
\gamma_{\mathrm{co}}=\frac{S_{\mathrm{VV}}}{S_{\mathrm{HH}}}, \\
\gamma_{\text {cross }}=\frac{S_{\mathrm{HV}}}{S_{\mathrm{HH}}}
\end{gathered}
$$

where $S$ is the complex scattering matrix; an asterisk $(*)$ represents the complex conjugate. The brackets $\langle\cdot\rangle$ represent ensemble averages of the observed data. There were approximately 34 pulses sent per incidence angle. An ensemble average was performed on those 34 pulses. Raw data were processed into range profiles and were averaged in the azimuth for each measured incidence angle. Polarimetric ratios $\gamma_{\text {co }}$ and $\gamma_{\text {cross }}$ are simply power ratios of backscattered energy. Polarimetric coherences and polarization ratios have demonstrated utility in reducing the ambiguities caused by the nonlinearity between system response and target properties. Regarding Arctic sea ice, some literature is available on the use of $\rho_{\mathrm{VVHH}}, \rho_{\mathrm{RRLL}}$, and $\gamma_{\mathrm{co}}$ at different EM frequencies. C-band backscatter coefficients $(\mathrm{HH}, \mathrm{HV}$, and $\mathrm{VV})$ and $\rho_{\mathrm{VVHH}}$ have been used to characterize various FYI types (compressed, rubble and ridge, and smooth) and multiyear ice [17]. Thin sea ice has been effectively discriminated from FYI using C-band $\gamma_{\mathrm{co}}$ ratio [18]. $\rho_{\mathrm{VVHH}}$ and $\gamma_{\mathrm{co}}$ have been used to discriminate Arctic leads using L-band radar signatures [19]. In a similar study, Wakabayashi et al. [20] described polarimetric characteristics of different FYI types (thin ice, smooth, and rough) using L-band $\rho_{\text {RRLL }}$ and $\gamma_{\text {co }}$ and showed the utility of coherences and ratios in discriminating ice types. Nakamura et al. [21] discriminated ice surface using $\gamma_{\text {co }}$ ratio in an observational study of lake ice using airborne L- and X-band SAR. These studies lack a holistic overview of the utility of different polarimetric coherences and ratios to discriminate thin FYI types in a MIZ.

2.3. Active Microwave Backscattering Data. C-band polarimetric backscattering data were collected using a completely stationary ship-mounted scatterometer system developed by ProSensing Inc., (Amherst, MA, USA) and mounted $7.56 \mathrm{~m}$ above the mean sea level on the port side of the Amundsen (Table 1). The system acquires backscatter and phase data in terms of the combinations of linear transmit-receive polarization combinations, $\mathrm{HH}, \mathrm{HV}, \mathrm{VH}$, and $\mathrm{VV}$ at incidence angles $20-60^{\circ}$ ( $5^{\circ}$ increments) over a $60^{\circ}$ azimuth range. The calibration of the instrument was performed through the methods given elsewhere [22, 23]. Polarimetric backscattering data were collected from homogeneous samples of snowcovered (dry and fresh) first-year ice (SCFYI), deformed FYI (DFYI), consolidated pancake ice (PI), snow-covered frost flowers (SCFF), and dense frost flowers (DFF) on different dates during November 2007. Data from each ice type sample comprised three to four contiguous scatterometer scans, which took up to 35 minutes to complete. The scatterometer had a footprint of $1.1 \mathrm{~m}^{2}$ in the range direction at a $45^{\circ}$ incidence angle [23] with the footprint increasing in size with incidence angle [22]. 


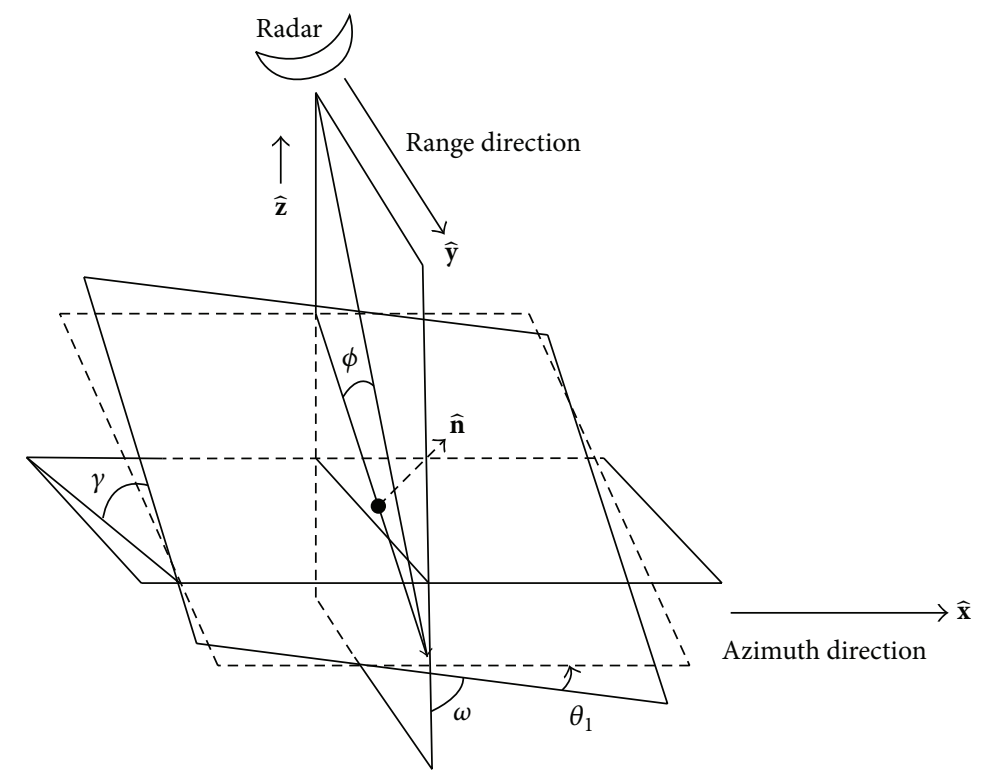

FIGURE 3: Illustration of scattering plane geometry with slight deviations in the orientation angles in azimuth $\left(\theta_{1}\right)$ and range directions $\left(\theta_{2}\right.$ : not shown), respectively, as means of two-dimensional surface roughness.

Towards objective 2, scan data for each ice type were grouped by incidence angle representing near $\left(20-25^{\circ}\right)$, mid $\left(35-40^{\circ}\right)$, and far $\left(55-60^{\circ}\right)$ range groupings. These groupings best represent the diversity of scattering mechanisms available across the acquired incidence angle range. In the near range, surface scattering is expected to dominate the measured C-band backscatter, while surface-volume scattering is increasingly expected to influence C-band backscatter beyond approximately $30^{\circ}$, that is, mid to far ranges [24]. Furthermore, combining data from adjacent incidence angles doubled the number of samples from 8 to 18 depending on ice type, although at the expense of range resolution. Scatterometer data had unequal number of data points in each range group, which does not fulfil parametric ANOVA requirements for statistical significance testing. Polarimetric coherences and ratios of ice types were tested for independence from each other for each incidence angle grouping. Testing was done using the nonparametric Kruskal-Wallis statistic, with $\alpha=0.01$ significance level (one tailed) used as the threshold for statistical independence.

2.4. Surface Roughness and Circular Coherence. In pursuit of objective 1, a polarimetric backscattering model is used which is mainly a Bragg backscattering (coherent scattering) model modified for surface roughness considering the surface slope by slightly changing the tilt of the surface from the horizontal. Microwave measurements of surface roughness using co- or crosspolarization backscattered power are most successful in flat areas. In sea ice microwave remote sensing, the dielectric constant and topography (slope in range and azimuth) are important. According to (22) in the one-dimensional scattering model of [13], the circular coherence is only sensitive to surface roughness. Surface roughness has been considered as a change in the slope of ice in azimuth and ground range directions $[13,16,25]$. This is implemented mathematically in the Bragg backscattering model by considering roughness as a depolarizer which conforms to reflection symmetry; that is, the backscattering properties are identical on either side of the plane of incidence and $\mathrm{HV}=\mathrm{VH}[25,26]$. The distribution of azimuth slope angles $\theta_{1}$ is considered as one-dimensional Gaussian distributed [13].

The rotation matrix [16] and the coherency matrix [13] are calculated after introducing the rotation in azimuth anticlockwise about range direction. In this case, $\rho_{\text {RRLL }}$ is derived as [13]

$$
\rho_{\mathrm{RRLL}}=e^{-8 \sigma_{\theta_{1}}^{2}},
$$

where $\sigma_{\theta_{1}}$ is the standard deviation of the orientation angle distribution in azimuth direction and $\theta_{1}$ is slope angle in azimuth direction. From (8), the $\rho_{\text {RRLL }}$ is only dependent on the orientation of ice surface in the range direction, or the standard deviation of the orientation angle distribution (i.e., surface roughness). Here, the surface roughness is introduced through rotation by angle $\theta_{2}$ in the range direction anticlockwise about azimuth direction (Figure 3 ). Angle $\theta_{2}$ is not shown in Figure 3 due to complexity of the geometry. In this case also, the corresponding distribution of shift in orientation angle is Gaussian distributed.

The new rotation matrix $U_{2}$ is given by

$$
U_{2}=\left[\begin{array}{ccc}
\cos 2 \theta_{2} & 0 & -\sin 2 \theta_{2} \\
0 & 1 & 0 \\
\sin 2 \theta_{2} & 0 & \cos 2 \theta_{2}
\end{array}\right] .
$$

The new averaged coherency matrix over the Gaussian distribution $p\left(\theta_{2}\right)$ can be calculated as

$$
\langle T\rangle_{\theta_{2}}=\left[\begin{array}{ccc}
\zeta A & \mu B & 0 \\
\mu B^{*} & 2 C & 0 \\
0 & 0 & (1-\zeta) A
\end{array}\right],
$$


where $\mu\left(\theta_{2}\right)=\int \cos 2 \theta_{2} p\left(\theta_{2}\right) d \theta_{2}$ and $\zeta\left(\theta_{2}\right)=\int \cos ^{2} 2 \theta_{2}$ $p\left(\theta_{2}\right) d \theta_{2}$. $B$, a part of an element of coherency matrix, is defined according to scattering matrix, $S$ [13]. $B^{*}$ is the conjugate of $B$. Both $B^{*}$ and $B$ are not used in the computation of $\rho_{\text {RRLL }}$.

The $\rho_{\text {RRLL }}$ can be computed as

$$
\begin{gathered}
\rho_{\mathrm{RRLL}}=\frac{T_{22}-T_{33}}{T_{22}+T_{33}}=\frac{2 C-\left(1-\zeta\left(\theta_{2}\right)\right) A}{2 C+\left(1-\zeta\left(\theta_{2}\right)\right) A}, \\
\rho_{\mathrm{RRLL}}=\frac{4 C-\left(1-e^{-8 \sigma_{\theta_{2}}^{2}}\right) A}{4 C+\left(1-e^{-8 \sigma_{\theta_{2}}^{2}}\right) A},
\end{gathered}
$$

where $A=\left|S_{\mathrm{HH}}+S_{\mathrm{VV}}\right|^{2}, C=(1 / 2)\left|S_{\mathrm{HH}}-S_{\mathrm{VV}}\right|^{2}$, and $\zeta\left(\theta_{2}\right)=$ $(1 / 2)\left(1+e^{-8 \sigma_{\theta_{2}}^{2}}\right) \cdot T_{i j}$ represents $(i, j)$ th element of the matrix, $\langle T\rangle_{\theta_{2}}$ given in (10).

Given the above, the $\rho_{\mathrm{RRLL}}$ is dependent on the standard deviation of the orientation angle distribution in range and the dielectric constant of the surface. Thus, it is shown that the new $\rho_{\text {RRLL }}$ is exponentially changing with the change in orientation angle in the azimuth direction, but it behaves in a way given by (12) and is dependent on both surface roughness (standard deviation) and the dielectric constant (scattering matrix) of the surface when roughness in two directions is considered. In our model, when two-dimensional roughness is considered, circular coherence is observed to be sensitive to both surface roughness and dielectric constant, thus, making it difficult to differentiate roughness. 2D model being more realistic requires further considerations of separating dielectrics from roughness.

Now, the slope-induced roughness is examined in the range direction only. Lee et al. [16] gave a relationship between slope in azimuth, slope in ground range, radar look angle $(\phi)$, and rotation in azimuth. Schuler et al. [13] expressed this relationship in terms of root mean square (rms) surface height $(s)$ and correlation length $(l)$, assuming that the range slope and orientation in azimuth are small perturbations around their means,

$$
\rho_{\mathrm{RRLL}}=e^{-16\left(s^{2} / l^{2} \sin ^{2} \phi\right)} .
$$

Figure 4 shows the incidence angle dependence of $\rho_{\text {RRLL }}$ by varying the $s^{2} / l^{2}$ ratio. As the roughness increases, $\rho_{\text {RRLL }}$ decreases. For $l \gg s$, that is, the surface is very smooth, the maximum value of $\rho_{\text {RRLL }}$ approaches unity. $\rho_{\text {RRLL }}$ decreases exponentially from unity to a fixed value of $s^{2} / l^{2}$ ratio at a particular incidence angle. A rough surface yields a smaller $\rho_{\text {RRLL }}$, which increases with increasing radar look angle. The range of $s^{2} / l^{2}$ for the presented ice classes is expected to lie between 0.001 and 0.1 [27].

The relationship between slopes in azimuth and range direction is further demonstrated. Corresponding shifts and radar incidence angle are given by (see Appendix B),

$$
\begin{aligned}
\frac{\tan \omega}{\tan \theta_{1}}= & \sin \theta_{2}(\tan \gamma \cdot \sin \phi+\cos \phi) \\
& +\cos \theta_{2}(-\tan \gamma \cdot \cos \phi+\sin \phi),
\end{aligned}
$$

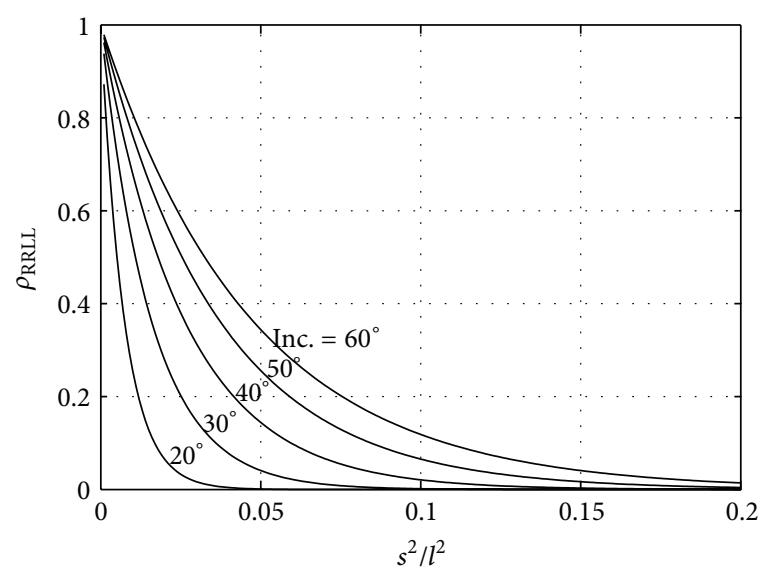

FIGURE 4: $\rho_{\text {RRLL }}$ varying with squared ratio of rms surface height and surface correlation length; $\rho_{\text {RRLL }}$ decays exponentially; however, it decays faster at steep incidence angles.

where $\tan \omega$ is azimuth slope, $\tan \gamma$ is range slope, $\theta_{1}$ and $\theta_{2}$ are the perturbations in orientation in azimuth and range directions, respectively, and $\phi$ is radar look angle. Figure 4 represents the case when orientation shift in the range direction is observed. In a sea ice remote sensing context, both surface roughness and the dielectric constant of ice affect $\rho_{\text {RRLL }}$ when slope is changed in azimuth direction, whereas only surface roughness affects $\rho_{\text {RRLL }}$ when slope is changed in range direction.

\section{Field Results}

3.1. Sea Ice Type Discrimination (Coherences and Ratios). The date and hour of scatterometer data acquisitions corresponding to each sea ice type, as well as coincident meteorological parameters, namely, wind speed, air temperature, and relative humidity, are provided in Table 2 . The photographs of the selected ice samples are shown in Figure 2. With the exception of wind speed, there is negligible variation in meteorological conditions between ice type scans. As such, it is expected that between-scan, temperature-induced effects on the dielectric properties, and backscattering intensities from the different ice types are negligible.

Figure 5 shows backscattering coefficients for co- $(\mathrm{HH}$ and $\mathrm{VV}$ ) and crosspolarization (HV) configurations of each ice type. The two frost flower cases (DFF and SCFF) are plotted separately to exemplify differences in backscattering behavior on the basis of their different frost flower concentrations. The DFF and SCFF have a visually measured concentration of approximately $>95 \%$ and $20 \%$, respectively. While SCFYI is visually separable using $\mathrm{HH}, \mathrm{HV}$, and VV polarizations at all incidence angles (low backscatter), PI and DFYI signatures overlap and are difficult to separate from each other. This may be indicative of PI geometry within the scatterometer footprint, as PI comprises a series of upturned edges and flat areas of ice (see Figure 2). The curvature of upturned PI edges causes a backscatter response similar to that caused by the deformations (upturned ice) in the DFYI. 
TABLE 2: Meteorological parameters associated with each ice type on different dates.

\begin{tabular}{lcccc}
\hline & Sea ice type & Wind speed $(\mathrm{m} / \mathrm{s})$ & Air temperature $\left({ }^{\circ} \mathrm{C}\right)$ & Relative humidity $\%$ \\
\hline Nov. 15, 2007 (Stn. 1117, 1400 hrs) & SCFYI & 14.4 & -16.0 & 85 \\
Nov. 19, 2007 (Stn. 1100, 0030 hrs) & DFYI & 13.9 & -16.2 & 73 \\
Nov. 20, 2007 (Stn. 1910, 0300 hrs) & PI & 2.6 & -13.5 & 79 \\
Nov. 21, 2007 (Stn. 437, 1630 hrs) & SCFF & 5.1 & -16.2 & 82 \\
Nov. 25, 2007 (Stn. 1812, 2100 hrs) & DFF & 3.6 & -16.6 & 86 \\
\hline
\end{tabular}

TABLE 3: Mean C-band polarimetric coherences and ratios of selected ice types, for near (N), middle (M), and far (F) range incidence angle groupings (also shown graphically in Figure 6). The number of data samples is: SCFYI, $N=14$; DFYI, $N=8 ; \mathrm{PI}, N=14 ; \mathrm{SCFF}, N=18$; DFF, $N=10$.

\begin{tabular}{|c|c|c|c|c|c|}
\hline & $\rho_{\mathrm{VVHH}}$ & $\rho_{\mathrm{HHVH}}$ & $\rho_{\text {RRLL }}$ & $\gamma_{\mathrm{co}}(\mathrm{dB})$ & $\gamma_{\text {cross }}(\mathrm{dB})$ \\
\hline \multicolumn{6}{|c|}{ SCFYI } \\
\hline $\mathrm{N}$ & 0.95 & 0.09 & 0.47 & 0.40 & -16.44 \\
\hline M & 0.81 & 0.09 & 0.65 & 3.64 & -13.72 \\
\hline $\mathrm{F}$ & 0.55 & 0.08 & 0.81 & 4.54 & -12.25 \\
\hline \multicolumn{6}{|l|}{ DFYI } \\
\hline $\mathrm{N}$ & 0.88 & 0.10 & 0.42 & 1.36 & -12.38 \\
\hline M & 0.91 & 0.08 & 0.52 & 2.47 & -12.94 \\
\hline $\mathrm{F}$ & 0.58 & 0.05 & 0.58 & 1.86 & -11.40 \\
\hline \multicolumn{6}{|l|}{ PI } \\
\hline $\mathrm{N}$ & 0.96 & 0.04 & 0.61 & 1.78 & -16.89 \\
\hline M & 0.84 & 0.04 & 0.61 & 1.89 & -13.73 \\
\hline $\mathrm{F}$ & 0.80 & 0.05 & 0.59 & 2.10 & -12.70 \\
\hline \multicolumn{6}{|l|}{ SCFF } \\
\hline $\mathrm{N}$ & 0.96 & 0.07 & 0.73 & 0.89 & -17.88 \\
\hline M & 0.89 & 0.07 & 0.70 & -0.59 & -15.83 \\
\hline $\mathrm{F}$ & 0.66 & 0.05 & 0.77 & 0.46 & -14.08 \\
\hline \multicolumn{6}{|l|}{ DFF } \\
\hline $\mathrm{N}$ & 0.84 & 0.15 & 0.35 & 2.41 & -09.71 \\
\hline M & 0.91 & 0.15 & 0.59 & 3.65 & -12.06 \\
\hline $\mathrm{F}$ & 0.79 & 0.12 & 0.72 & 3.23 & -12.23 \\
\hline
\end{tabular}

DFF and SCFF are differentiable at HV and VV polarization at mid to far incidence angles.

Mean coherences and polarization ratios for each ice type as a function of incidence angle grouping are documented in Table 3. All sea ice types show high $\rho_{\mathrm{VVHH}}$, indicating low depolarisation and primarily single (surface) backscattering. The $\rho_{\mathrm{HHVH}}$ for DFF is notably higher than that from the other ice types, which points to strong depolarisation caused by the frost flower structures. As shown in the previous section, a low value of $\rho_{\text {RRLL }}$ indicates a rougher surface. At mid to far ranges in Table 3 , the $\rho_{\mathrm{RRLL}}$ for DFYI is the lowest while for SCFYI it is the highest, which is consistent with the roughest and smoothest ice types, respectively. Furthermore, for frost flower-covered surfaces, that is, SCFF and DFF, the lower magnitude of $\rho_{\mathrm{RRLL}}$ is consistent with the higher concentration of frost flowers. At near-incidence angle range, the SCFYI shows higher roughness (i.e., lower $\rho_{\mathrm{RRLL}}=0.47$, Table 3) compared to that of PI (0.61). This may be due to the fact that the snow is dry and has low salinity, which allows EM waves to penetrate through the snow. This is likely to provide roughness of snow-ice interface rather than air-snow interface. At mid incidence angle range, as expected, SCFYI shows lower roughness (i.e., higher $\rho_{\text {RRLL }}=0.65$, Table 3 ) compared to that of PI (0.61). Mid incidence angles are well suited for differentiating ice roughness/types using $\rho_{\mathrm{RRLL}}$.

Looking at polarization ratios in Table 3 , the $\gamma_{\text {co }}$ increases rapidly with incidence angle and is the highest at the far range for SCFYI. The $\gamma_{\text {co }}$ ratio is also high for DFF, but it remains fairly constant across all incidence angles. High $\gamma_{\text {co }}$ is also representative of saline ice surface (FYI in this case) or surface scattering. The presence of dry snow $(\sim 1-2 \mathrm{~cm})$ allows the EM waves to penetrate through snow, which causes reflection from the ice-snow interface. The $\gamma_{\text {co }}$ behavior of SCFYI is consistent with that of a surface, which is very smooth (i.e., a Bragg surface), where the ratio between backscattered $\mathrm{H}$ and $\mathrm{V}$ is only dependent on incidence angle and dielectric constant [28]. On the other hand, the $\gamma_{\text {co }}$ behavior for DFF is consistent with that of a rough surface exhibiting backscatter from features with preferential vertical orientation [22]. Including the $\gamma_{\text {cross }}$ ratio in this comparison further supports 


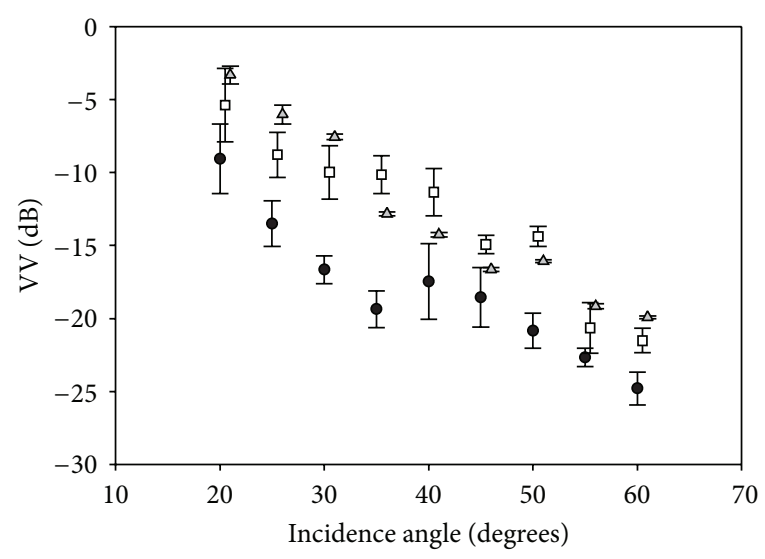

(a)

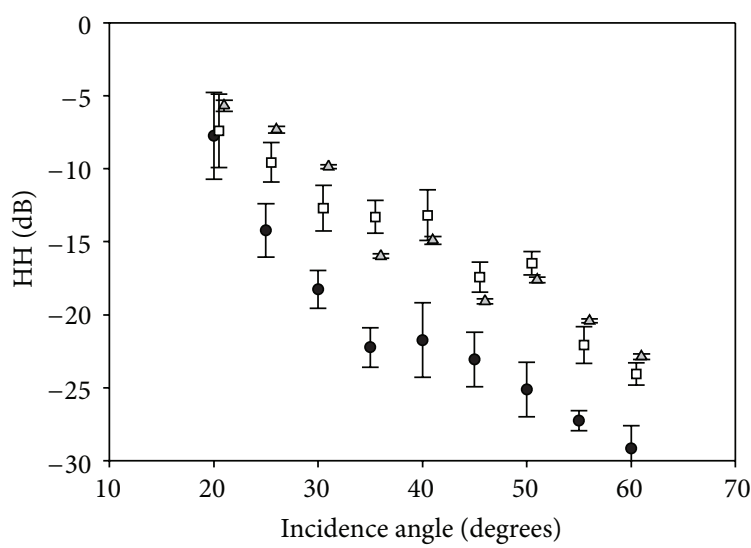

(c)

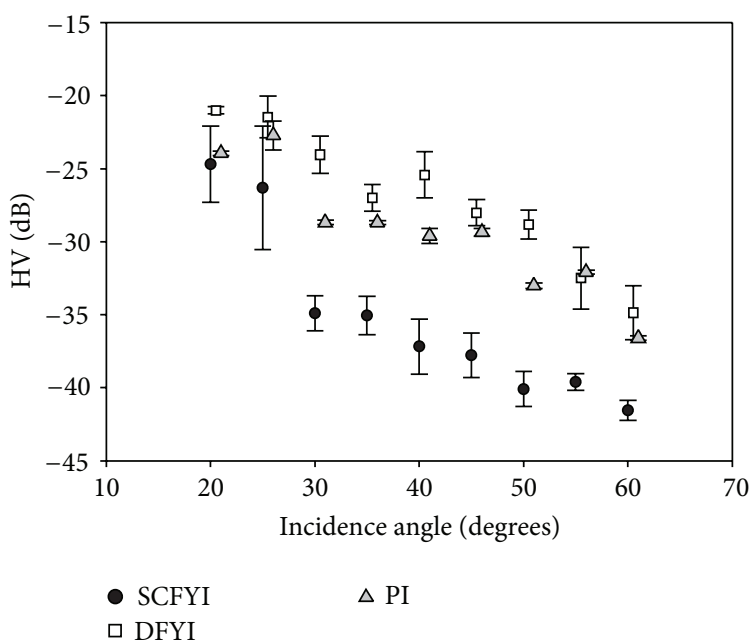

(e)

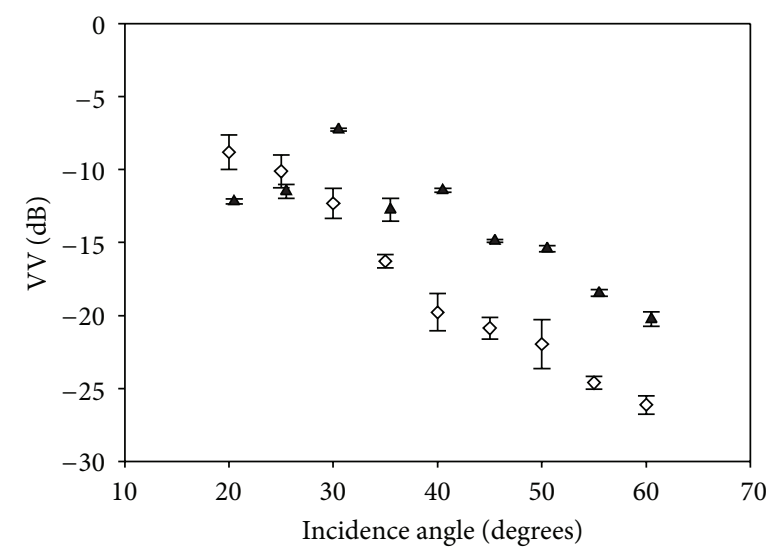

(b)

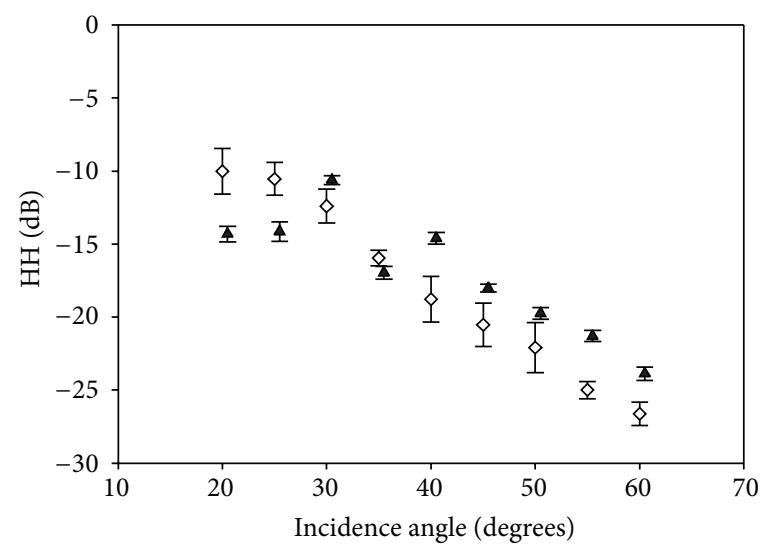

(d)

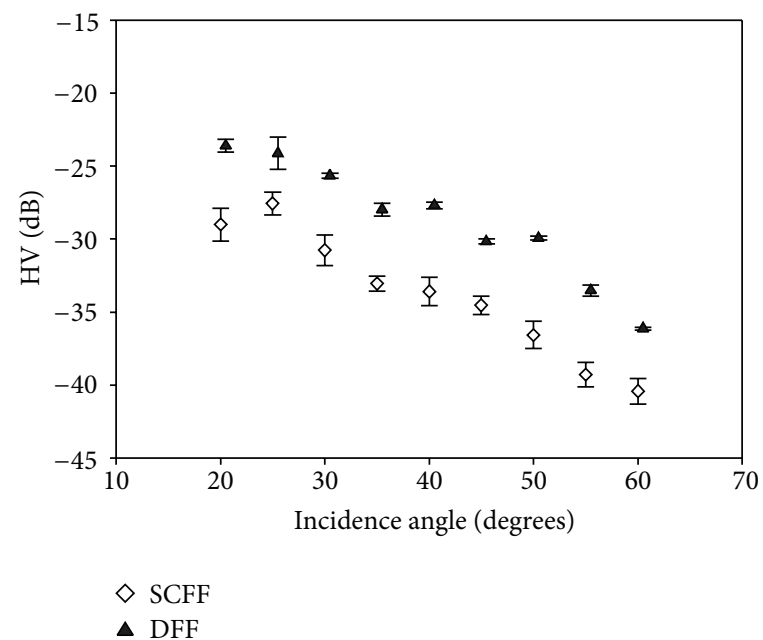

(f)

FIGURE 5: Co- (HH and VV) and cross- (HV) polarization backscatter intensities of snow-covered first-year sea ice (SCFYI), deformed firstyear sea ice (DFYI), consolidated pancake ice (PI), snow-covered frost flowers (SCFF), and dense frost flowers (DFF).

the distinction in backscattering mechanisms. The near range $\gamma_{\text {cross }}$ ratio is much smaller for SCFYI than DFF, indicating it to be much smoother. The DFYI and DFF show the highest overall $\gamma_{\text {cross }}$, due to multiple scattering within deformities for DFYI and depolarisation caused by frost flowers for DFF.

Figure 6 shows box plots of coherences and polarization ratios of each ice type. Table 4 provides the significance values resulting from statistical tests for independence between each ice type based on a given coherence or ratio. All data in Figure 6 and Table 4 are based on the aforementioned incidence angle groupings from near to far range and, together, facilitate a conceptual approach to assessing the utility of each parameter for distinguishing ice types within an MIZ. Summarizing Figure 6 and Table 4 , the near range $\rho_{\mathrm{HHVH}}$ and 

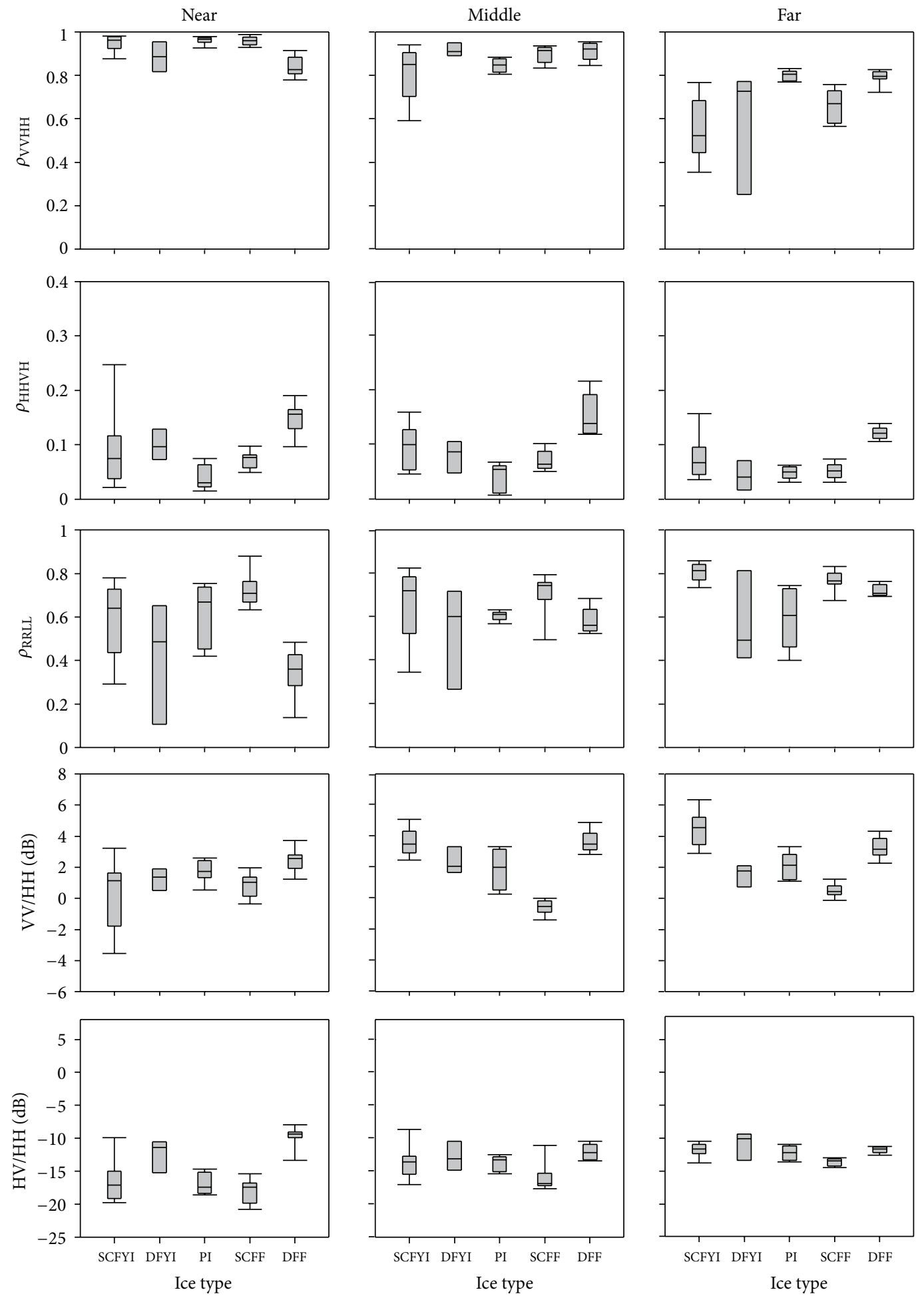

FIGURE 6: Box plots of coherences and polarization ratios of ice types based on near, middle, and far range incidence angle groupings. Significance values are provided in Table 4.

$\gamma_{\text {cross }}$ provide the greatest separation between classes, while the far range $\rho_{\mathrm{VVHH}}$ and $\gamma_{\mathrm{co}}$ provide the greatest separation. By combining $\gamma_{\text {co }}$ (far) with either of $\rho_{\mathrm{HHVH}}$ or $\gamma_{\text {cross }}$ (near), all ice types are independent of each other. From Figure 4 it is known that a lower $\rho_{\mathrm{RRLL}}$ is associated with a rougher ice surface.

It is demonstrated using theory that lower values of $\rho_{\mathrm{RRLL}}$ indicate a rougher ice surface. Referring to Figures 4 and 6 , 
TABLE 4: Matrix of significance values from non-parametric Kruskal-Wallis tests for independence between ice types based on polarimetric parameters and near $(\mathrm{N})$, middle $(\mathrm{M})$, and far $(\mathrm{F})$ range groupings. The number of data samples is: $\mathrm{SCFYI}, N=14 ; \mathrm{DFYI}, N=8 ; \mathrm{PI}, N=14$; SCFF, $N=18$; DFF, $N=10$.

\begin{tabular}{|c|c|c|c|c|c|c|c|c|c|c|c|c|c|c|c|}
\hline & \multicolumn{5}{|c|}{ Near range } & \multicolumn{5}{|c|}{ Middle range } & \multicolumn{5}{|c|}{ Far range } \\
\hline & SCFYI & DFYI & PI & SCFF & DFF & SCFYI & DFYI & PI & SCFF & DFF & SCFYI & DFYI & PI & SCFF & DFF \\
\hline \multicolumn{16}{|l|}{$\begin{array}{l}\rho_{\mathrm{VVHH}} \\
\quad \text { SCFYI }\end{array}$} \\
\hline DFYI & .285 & & & & & .015 & & & & & .094 & & & & \\
\hline PI & .028 & .094 & & & & .509 & .000 & & & & .000 & .001 & & & \\
\hline SCFF & .463 & .119 & .002 & & & .011 & .322 & .001 & & & .014 & .199 & .000 & & \\
\hline DFF & .004 & .013 & .028 & .000 & & .005 & .483 & .000 & .000 & & .000 & .004 & .420 & .000 & \\
\hline \multicolumn{16}{|l|}{$\begin{array}{l}\rho_{\mathrm{HHVH}} \\
\quad \text { SCFYI }\end{array}$} \\
\hline DFYI & .201 & & & & & .201 & & & & & .035 & & & & \\
\hline PI & .006 & .000 & & & & .005 & .005 & & & & .018 & .221 & & & \\
\hline SCFF & .429 & .008 & .000 & & & .125 & .156 & .001 & & & .046 & .184 & .277 & & \\
\hline DFF & .002 & .002 & .000 & .000 & & .001 & .000 & .000 & .000 & & .001 & .000 & .000 & .000 & \\
\hline \multicolumn{16}{|l|}{$\begin{array}{l}\rho_{\text {RRLL }} \\
\quad \text { SCFYI }\end{array}$} \\
\hline DFYI & .308 & & & & & .048 & & & & & .030 & & & & \\
\hline PI & .164 & .106 & & & & .082 & .513 & & & & .000 & .357 & & & \\
\hline SCFF & .006 & .001 & .039 & & & .418 & .005 & .002 & & & .015 & .023 & .000 & & \\
\hline DFF & .023 & .197 & .000 & .000 & & .069 & .483 & .170 & .003 & & .000 & .042 & .117 & .002 & \\
\hline \multicolumn{16}{|l|}{$\gamma_{\mathrm{co}}$} \\
\hline DFYI & .285 & & & & & .018 & & & & & .001 & & & & \\
\hline PI & .028 & .094 & & & & .001 & .183 & & & & .000 & .308 & & & \\
\hline SCFF & .463 & .119 & .002 & & & .000 & .000 & .000 & & & .000 & .001 & .000 & & \\
\hline DFF & .004 & .013 & .028 & .000 & & .466 & .017 & .001 & .000 & & .000 & .003 & .005 & .000 & \\
\hline \multicolumn{16}{|l|}{$\begin{array}{l}\gamma_{\text {cross }} \\
\quad \text { SCFYI }\end{array}$} \\
\hline DFYI & .005 & & & & & .149 & & & & & .041 & & & & \\
\hline PI & .437 & .001 & & & & .214 & .357 & & & & .164 & .041 & & & \\
\hline SCFF & .118 & .000 & .179 & & & .006 & .005 & .001 & & & .000 & .013 & .001 & & \\
\hline DFF & .000 & .010 & .000 & .000 & & .004 & .204 & .006 & .000 & & .420 & .042 & .354 & $.000^{\#}$ & \\
\hline
\end{tabular}

\#Bold numbers indicate important significant values.

$\rho_{\text {RRLL }}$ is high for increasing incidence angles and for low surface roughness. This is only true for SCFYI and SCFF. In the presence of dry and fresh snow the volume contribution from FYI can be ignored, in which case $\rho_{\text {RRLL }}$ dictates surface roughness of the snow-ice interface rather than air-snow interface. The coherence estimates are negligibly affected by the signal-to-noise ratio (typically $>10 \mathrm{~dB}$ ) during the processing of scatterometer data. These coherences can also be computed using polarimetric observations from spacebased platforms.

\section{Summary and Conclusions}

The one-dimensional backscatter model of Schuler et al. [13] was modified to two dimensions of surface roughness by considering deviation in the orientation angles (i.e., the slopes) in azimuth and range direction simultaneously as an improvement in the model. Parameters derived from the fully polarimetric C-band microwave backscatter response from sea ice targets were demonstrated to have utility for small-scale ( $\mathrm{cm}$ level) sea ice roughness identification. Circular coherence has been investigated for its usefulness in discriminating surface roughness among other polarimetric parameters. Circular coherence is theoretically shown to detect measurement sensitivity to surface roughness.

The conclusions with reference to objective 1 are as follows. It was shown theoretically that the $\rho_{\text {RRLL }}$ decreases exponentially with increasing surface roughness. However, $\rho_{\text {RRLL }}$ responds to both roughness (standard deviation) and dielectric constant (scattering matrix) of the surface in the case when the orientations of the ice target in azimuth 
direction are changed. It remains challenging to separate roughness effects from the dielectric effects using C-band backscatter measurements. $\rho_{\text {RRLL }}$ independently does not provide a robust sea ice roughness discrimination scheme. However, $\rho_{\text {RRLL }}$ provides an improved insight of sea ice surface roughness combined with other polarimetric coherences and channel ratios in the chosen samples. The experimental data also show that rougher ice surface exhibits lower mean value of $\rho_{\text {RRLL }}$ (Table 3, Figure 4), though a complete validation of the effect of changing orientations of ice floe on $\rho_{\text {RRLL }}$ is required. This would require polarimetric backscattering data and surface roughness information to be acquired at different lines of sight (i.e., orientation of ice floes). Unfortunately, difficulties associated with extreme weather conditions and limitations to navigation in the Arctic restrict such detailed data acquisition; however, a tank experiment could be a useful alternative.

The utility of C-band polarimetric coherences and ratios is addressed in the light of objective 2 as follows: for coherences, $\rho_{\mathrm{VVHH}}$ is smaller at far range incidence angles for all ice types. $\rho_{\mathrm{HHVH}}$ is less sensitive to roughness and is not a good discriminator of roughness. Regarding channel ratios, based on Kruskal-Wallis test, $\gamma_{\mathrm{co}}$ is more sensitive to increasing surface roughness compared to $\gamma_{\text {cross }}$ and demonstrates utility for separating ice types compared to the other observed parameters.

The knowledge obtained through surface-based polarimetric coherences and ratios can readily be extended to discriminate sea ice roughness on small scales using Cband microwave satellites (currently in orbit RADARSAT2, RISAT-1). Future work will be to develop an algorithm combining all polarimetric coherences and ratios to discriminate individual ice type in a MIZ. These observations may become particularly useful for satellite measurements once planned SAR constellations (Sentinel series) systems are available, as currently planned by National Aeronautics and Space Administration and European Space Agency.

\section{Appendices}

\section{A. Derivation of $\rho_{R R L L}$}

To understand how to extract best information from the scattering matrix $\mathbf{S}$, it is represented by the vector, $\mathbf{V}$, built as follows:

$$
\begin{gathered}
\mathbf{S}=\left[\begin{array}{cc}
\mathrm{HH} & \mathrm{HV} \\
\mathrm{VH} & \mathrm{VV}
\end{array}\right] ; \quad \mathbf{k}=\mathbf{V}(\mathbf{S})=\frac{1}{2} \operatorname{Tr}([\mathbf{S}] \psi), \\
\mathbf{k}=\left(\begin{array}{llll}
k_{0} & k_{1} & k_{2} & k_{3}
\end{array}\right)^{\mathrm{T}},
\end{gathered}
$$

where $\psi$ is a basis matrix which is constructed as an orthonormal set under the Hermitian inner product. The polarimetric coherency matrix is based on linear combinations arising from Pauli matrices [28] given as

$$
\psi \equiv \sqrt{2}\left[\begin{array}{ll}
1 & 0 \\
0 & 1
\end{array}\right] \sqrt{2}\left[\begin{array}{cc}
1 & 0 \\
0 & -1
\end{array}\right] \sqrt{2}\left[\begin{array}{ll}
0 & 1 \\
1 & 0
\end{array}\right] \sqrt{2}\left[\begin{array}{cc}
0 & -i \\
i & 0
\end{array}\right] .
$$

The factor of $\sqrt{2}$ arises from the requirement to keep $\operatorname{Tr}([\mathbf{S}])$, the total power scattered, an invariant. The target vector in above base is constructed as

$$
\begin{aligned}
\mathbf{k}= & \frac{1}{\sqrt{2}} \\
& \times\left[\left(S_{\mathrm{HH}}+S_{\mathrm{VV}}\right)\left(S_{\mathrm{HH}}-S_{\mathrm{VV}}\right)\left(S_{\mathrm{HV}}+S_{\mathrm{VH}}\right) i\left(S_{\mathrm{HV}}-S_{\mathrm{VH}}\right)\right]^{T} .
\end{aligned}
$$

From the vector form of scattering matrix, the Pauli coherency matrix is generated from the outer product of the vector with its conjugate transpose as

$$
\mathbf{T}_{4}=\left\langle\mathbf{k} \cdot \mathbf{k}^{* T}\right\rangle .
$$

For reciprocal target matrix (as in monostatic backscattering), $S_{\mathrm{HV}}=S_{\mathrm{VH}}$; the four-dimensional polarimetric coherency matrix reduced to three-dimensional polarimetric coherency matrix is obtained as

$$
\mathbf{T}_{\mathbf{3}}=\left[\begin{array}{ccc}
\left\langle\left|S_{\mathrm{HH}}+S_{\mathrm{VV}}\right|^{2}\right\rangle & \left\langle\left(S_{\mathrm{HH}}+S_{\mathrm{VV}}\right)\left(S_{\mathrm{HH}}-S_{\mathrm{VV}}\right)^{*}\right\rangle & 2\left\langle\left(S_{\mathrm{HH}}+S_{\mathrm{VV}}\right) S_{\mathrm{HV}}^{*}\right\rangle \\
\left\langle\left(S_{\mathrm{HH}}-S_{\mathrm{VV}}\right)\left(S_{\mathrm{HH}}+S_{\mathrm{VV}}\right)^{*}\right\rangle & \left\langle\left|S_{\mathrm{HH}}-S_{\mathrm{VV}}\right|^{2}\right\rangle & 2\left\langle\left(S_{\mathrm{HH}}-S_{\mathrm{VV}}\right) S_{\mathrm{HV}}^{*}\right\rangle \\
2\left\langle S_{\mathrm{HV}}\left(S_{\mathrm{HH}}+S_{\mathrm{VV}}\right)^{*}\right\rangle & 2\left\langle S_{\mathrm{HV}}\left(S_{\mathrm{HH}}-S_{\mathrm{VV}}\right)^{*}\right\rangle & 4\left\langle\left|S_{\mathrm{HV}}\right|^{2}\right\rangle
\end{array}\right] .
$$

The $\rho_{\text {RRLL }}$ is computed as $[28,29]$

$$
\rho_{\mathrm{RRLL}}=\frac{T_{22}-T_{33}}{T_{22}+T_{33}}=\frac{\left\langle\left|S_{\mathrm{HH}}-S_{\mathrm{VV}}\right|^{2}\right\rangle-4\left\langle\left|S_{\mathrm{HV}}\right|^{2}\right\rangle}{\left\langle\left|S_{\mathrm{HH}}-S_{\mathrm{VV}}\right|^{2}\right\rangle+4\left\langle\left|S_{\mathrm{HV}}\right|^{2}\right\rangle}
$$

where $T_{i j}$ represents the $(i, j)$ element of the matrix, $\mathbf{T}_{3}$, given in (A.5). For the one-dimensional polarimetric scattering model described elsewhere $[13,30], \rho_{\text {RRLL }}$ is expressed as independent of dielectrics, thus depending only on surface roughness. Fore more detailed, step by step derivation of $\rho_{\text {RRLL }}$, the reader is directed to [28-30].

\section{B.}

Here, the relationship between slope in azimuth and ground range, radar look angle, shift in azimuth, and shift in ground range is derived. The slope equation given by Lee et al. [16] does not include shift in range direction. Figure 3 shows the geometry of backscattering plane. Suppose that the backscattering plane is shifted in azimuth direction by angle 
$\theta_{1}$ and in range direction by angle $\theta_{2}$. $\widehat{\mathbf{n}}$ represents the surface normal on the backscattering plane before rotating:

$$
\begin{gathered}
\widehat{\mathbf{n}}=n_{1} \widehat{\mathbf{x}}+n_{2} \widehat{\mathbf{y}}+n_{3} \widehat{\mathbf{z}} \\
\widehat{\mathbf{N}}=\left[\begin{array}{ccc}
0 & -\sin \phi & \cos \phi \\
1 & 0 & 0 \\
0 & \cos \phi & \sin \phi
\end{array}\right]\left[\begin{array}{l}
n_{1} \\
n_{2} \\
n_{3}
\end{array}\right] \\
=\left[\begin{array}{c}
-n_{2} \sin \phi+n_{3} \cos \phi \\
n_{1} \\
n_{2} \cos \phi+n_{3} \sin \phi
\end{array}\right] .
\end{gathered}
$$

The surface normal changes after a shift in azimuth and range directions. The transformed normal is

$$
\widehat{\mathbf{n}}\left(\theta_{1}, \theta_{2}\right)=\left[\begin{array}{ccc}
1 & 0 & 0 \\
0 & \cos \theta_{1} & \sin \theta_{1} \\
0 & -\sin \theta_{1} & \cos \theta_{1}
\end{array}\right]\left[\begin{array}{ccc}
\cos \theta_{2} & 0 & -\sin \theta_{2} \\
0 & 1 & 0 \\
\sin \theta_{2} & 0 & \cos \theta_{2}
\end{array}\right] \widehat{\mathbf{N}} .
$$

If $\cos \theta_{1}=c_{1}$ and $\sin \theta_{2}=s_{2}$, and substitute $\widehat{\mathbf{N}}$ from (B.2), then (B.3) is

$$
=\left[\begin{array}{c}
-c_{2}\left(n_{2} \sin \phi+n_{3} \cos \phi\right)-s_{2}\left(n_{2} \cos \phi+n_{3} \sin \phi\right) \\
s_{1} s_{2}\left(-n_{2} \sin \phi+n_{3} \cos \phi\right)+n_{1} c_{1}+s_{1} c_{2}\left(n_{2} \cos \phi+n_{3} \sin \phi\right) \\
c_{1} s_{2}\left(-n_{2} \sin \phi+n_{3} \cos \phi\right)-n_{1} s_{1}+c_{1} c_{2}\left(n_{2} \cos \phi+n_{3} \sin \phi\right)
\end{array}\right] .
$$

After the rotation the surface normal is in new plane where the second component must be zero:

$$
\begin{aligned}
s_{1} s_{2}( & \left.-n_{2} \sin \phi+n_{3} \cos \phi\right)+n_{1} c_{1} \\
& +s_{1} c_{2}\left(n_{2} \cos \phi+n_{3} \sin \phi\right)=0 .
\end{aligned}
$$

With range slope, $\tan \gamma=-\left(n_{2} / n_{3}\right)$ and azimuth slope $\tan \omega=$ $-\left(n_{1} / n_{3}\right)$,

$$
\begin{aligned}
\frac{\tan \omega}{\tan \theta_{1}}= & \sin \theta_{2}(\tan \gamma \cdot \sin \phi+\cos \phi) \\
& +\cos \theta_{2}(-\tan \gamma \cdot \cos \phi+\sin \phi) .
\end{aligned}
$$

In (B.6), if the perturbation in orientation in range direction is zero, that is, $\theta_{2}=0$, it reduces to equation given by Lee et al. [16].

\section{Acknowledgments}

The main funding for the project was provided by the IPYCanada, the Natural Sciences and Engineering Research Council (NSERC), and the Canada Research Chairs (CRC) Program, each to DGB. Authors gratefully thank icebreaker Amundsen crew for their exceptional support in acquiring data and excellent navigation during overwintering in the Arctic. They thank their colleagues from various Canadian and international organizations who helped in deployment and recuperation of instruments in the field. Authors thank Dr. Dustin Isleifson for data preprocessing and providing multiple and very useful reviews in improving the paper.

\section{References}

[1] R. Kwok and G. F. Cunningham, "Contribution of melt in the Beaufort Sea to the decline in Arctic multiyear sea ice coverage: 1993-2009," Geophysical Research Letters, vol. 37, Article ID L20501, 2010.

[2] R. Kwok and D. A. Rothrock, "Decline in Arctic sea ice thickness from submarine and ICESat records: 1958-2008," Geophysical Research Letters, vol. 36, Article ID L15501, 2009.

[3] S. V. Nghiem, I. G. Rigor, D. K. Perovich, P. Clemente-Colon, J. W. Weatherly, and G. Neumann, "Rapid reduction of Arctic perennial sea ice," Geophysical Research Letters, vol. 34, Article ID L19504, 2007.

[4] M. G. McPhee, J. H. Morison, and F. Nilsen, "Revisiting heat and salt exchange at the ice-ocean interface: ocean flux and modelling considerations," Journal of Geophysical Research, vol. 113, Article ID C06014, 2008.

[5] E. L. Andreas, T. W. Horst, A. A. Grachev et al., "Parameterizing turbulent exchange over summer sea ice and the marginal ice zone," Quarterly Journal of the Royal Meteorological Society, vol. 136, pp. 927-943, 2010.

[6] D. Lavoie, R. W. Macdonald, and K. L. Denman, "Primary productivity and export fluxes on the Canadian shelf of the Beaufort Sea: a modelling study," Journal of Marine Systems, vol. 75, no. 1-2, pp. 17-32, 2009.

[7] R. Kwok, E. Rignot, B. Holt, and R. Onstott, "Identification of sea ice types in spaceborne synthetic aperture radar data," Journal of Geophysical Research, vol. 97, no. 2, pp. 2391-2402, 1992.

[8] H. Melling, "Detection of features in first-year pack ice by synthetic aperture radar (SAR)," International Journal of Remote Sensing, vol. 19, no. 6, pp. 1223-1249, 1998.

[9] G. M. Wohl, "Operational sea ice classification from synthetic aperture radar imagery," Photogrammetric Engineering \& Remote Sensing, vol. 61, no. 12, pp. 1455-1462, 1995.

[10] D. G. Barber and E. F. LeDrew, "SAR sea ice discrimination using texture statistics: a multivariate approach," Photogrammetric Engineering \& Remote Sensing, vol. 57, no. 4, pp. 385-395, 1991.

[11] Q. A. Holmes, D. R. Nüesch, and R. A. Shuchman, “Textural analysis and real-time classification of sea-ice types using digital SAR data," IEEE Transactions on Geoscience and Remote Sensing, vol. 22, no. 2, pp. 113-120, 1984.

[12] S. V. Nghiem and C. Bertoia, "Study of multi-polarization Cband backscatter signatures for arctic sea ice mapping with future satellite SAR," Canadian Journal of Remote Sensing, vol. 27, no. 5, pp. 387-402, 2001.

[13] D. L. Schuler, J. S. Lee, D. Kasilingam, and G. Nesti, "Surface roughness and slope measurements using polarimetric SAR data," IEEE Transactions on Geoscience and Remote Sensing, vol. 40, no. 3, pp. 687-698, 2002.

[14] D. G. Barber and J. M. Hanesiak, "Meteorological forcing of sea ice concentrations in the southern Beaufort Sea over the period 1979 to 2000," Journal of Geophysical Research C, vol. 109, no. 6, pp. C06014-16, 2004.

[15] D. G. Barber, M. G. Asplin, Y. Gratton et al., "The International Polar Year (IPY) Circumpolar Flaw Lead (CFL) system study: overview and the physical system," Atmosphere, vol. 48, no. 4, pp. 225-243, 2010.

[16] J. S. Lee, D. L. Schuler, and T. L. Ainsworth, "Polarimetric SAR data compensation for terrain azimuth slope variation," IEEE 
Transactions on Geoscience and Remote Sensing, vol. 38, no. 5 I, pp. 2153-2163, 2000.

[17] R. Rignot and M. R. Drinkwater, "Winter sea-ice mapping from multi-parameter synthetic-aperture radar data," Journal of Glaciology, vol. 40, no. 134, pp. 31-45, 1994.

[18] T. Geldsetzer and J. J. Yackel, "Sea ice type and open water discrimination using dual co-polarized C-band SAR," Canadian Journal of Remote Sensing, vol. 35, no. 1, pp. 73-84, 2009.

[19] D. P. Winebrenner, L. D. Farmer, and I. R. Joughin, "On the response of polarimetric synthetic aperture radar signatures at 24-cm wavelength to sea ice thickness in Arctic leads," Radio Science, vol. 30, no. 2, pp. 373-402, 1995.

[20] H. Wakabayashi, T. Matsuoka, K. Nakamura, and F. Nishio, "Polarimetric characteristics of sea ice in the sea of okhotsk observed by airborne L-band SAR," IEEE Transactions on Geoscience and Remote Sensing, vol. 42, no. 11, pp. 2412-2425, 2004.

[21] K. Nakamura, H. Wakabayashi, K. Naoki, F. Nishio, T. Moriyama, and S. Uratsuka, "Observation of sea-ice thickness in the sea of okhotsk by using dual-frequency and fully polarimetric airborne SAR (Pi-SAR) data," IEEE Transactions on Geoscience and Remote Sensing, vol. 43, no. 11, pp. 2460-2468, 2005.

[22] T. Geldsetzer, J. B. Mead, J. J. Yackel, R. K. Scharien, and S. E. L. Howell, "Surface-based polarimetric C-band scatterometer for field measurements of sea ice," IEEE Transactions on Geoscience and Remote Sensing, vol. 45, no. 11, pp. 3405-3416, 2007.

[23] D. Isleifson, B. Hwang, D. G. Barber, R. K. Scharien, and L. Shafai, "C-band polarimetric backscattering signatures of newly formed sea ice during fall freeze-up," IEEE Transactions on Geoscience and Remote Sensing, vol. 48, no. 8, pp. 3256-3267, 2010.

[24] S. V. Nghiem, R. Kwok, S. H. Yueh, and M. R. Drinkwater, "Polarimetric signatures of sea ice 2. Experimental observations," Journal of Geophysical Research, vol. 100, no. C7, pp. 13681-13698, 1995.

[25] S. V. Nghiem, S. H. Yueh, R. Kwok, and F. K. Li, "Symmetry properties in polarimetric remote sensing," Radio Science, vol. 27, no. 5, pp. 693-711, 1992.

[26] S. H. Yueh, R. Kwok, and S. V. Nghiem, "Polarimetric backscattering and emission properties of targets with reflection symmetry," Radio Science, vol. 29, no. 6, pp. 1409-1420, 1994.

[27] F. D. Carsey, Ed., Microwave Remote Sensing of Sea Ice, American Geophysical Union, Washington, DC, USA, 1992.

[28] S. R. Cloude and E. Pottier, "A review of target decomposition theorems in radar polarimetry," IEEE Transactions on Geoscience and Remote Sensing, vol. 34, no. 2, pp. 498-518, 1996.

[29] J. S. Lee, D. L. Schuler, T. L. Ainsworth, E. Krogager, D. Kasilingam, and W. M. Boerner, "On the estimation of radar polarization orientation shifts induced by terrain slopes," IEEE Transactions on Geoscience and Remote Sensing, vol. 40, no. 1, pp. 30-41, 2002.

[30] I. Hajnsek, E. Pottier, and S. R. Cloude, "Inversion of surface parameters from polarimetric SAR," IEEE Transactions on Geoscience and Remote Sensing, vol. 41, no. 4, pp. 727-744, 2003. 

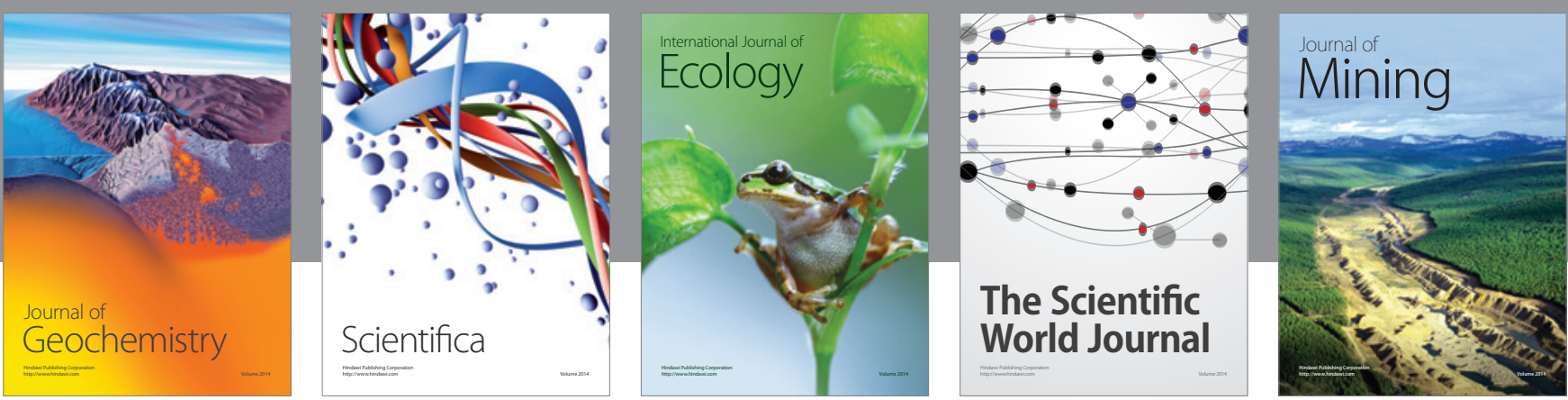

The Scientific World Journal
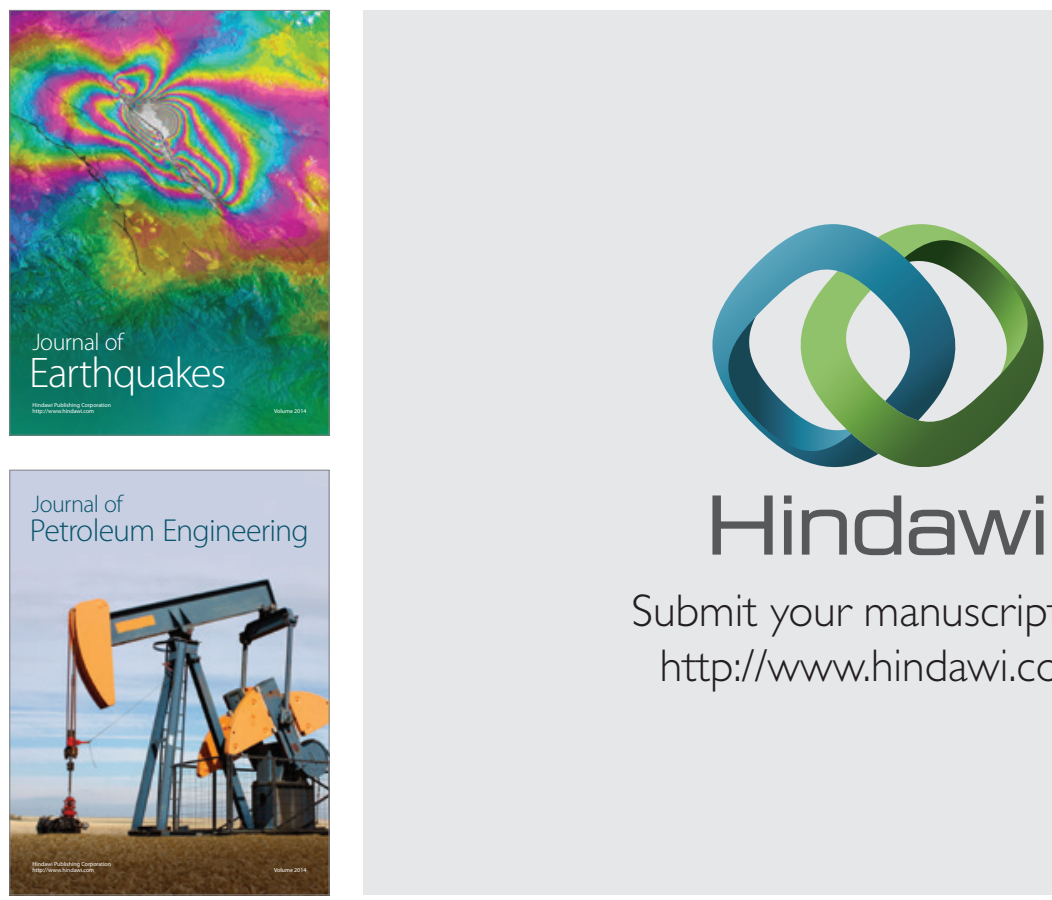

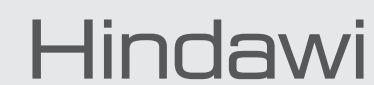

Submit your manuscripts at

http://www.hindawi.com
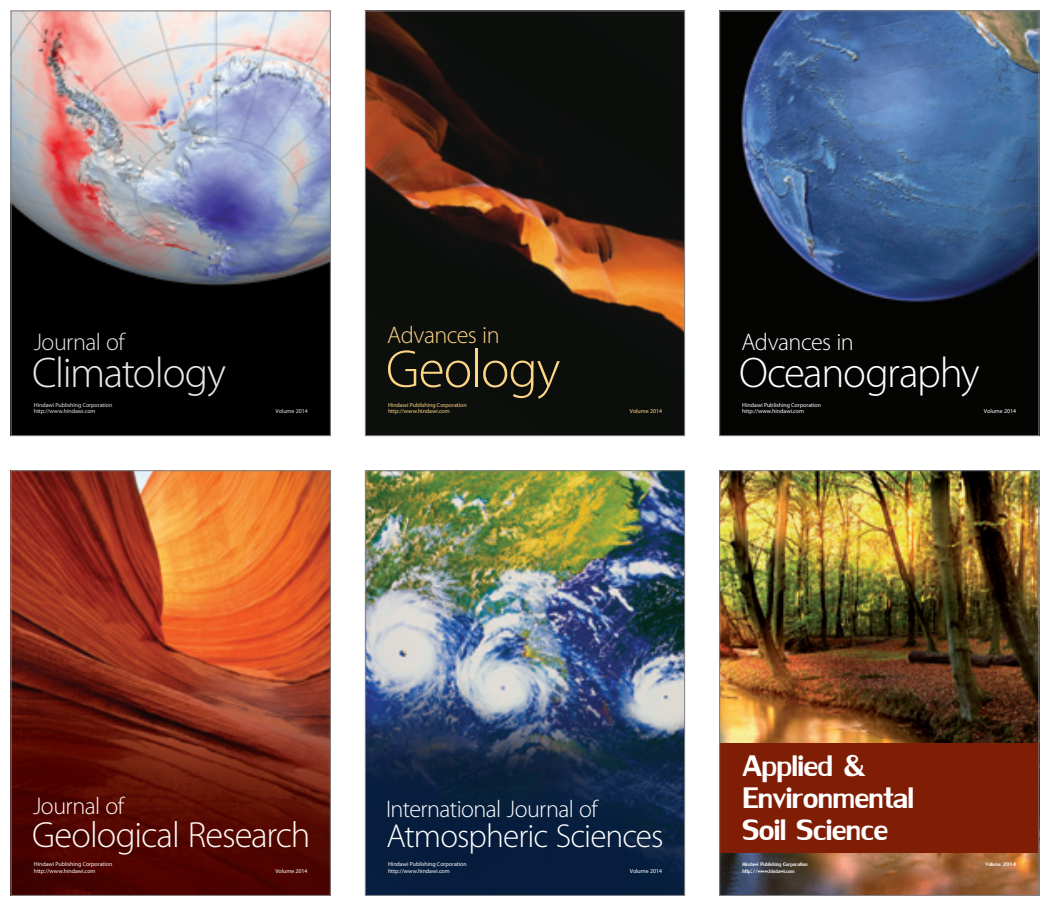
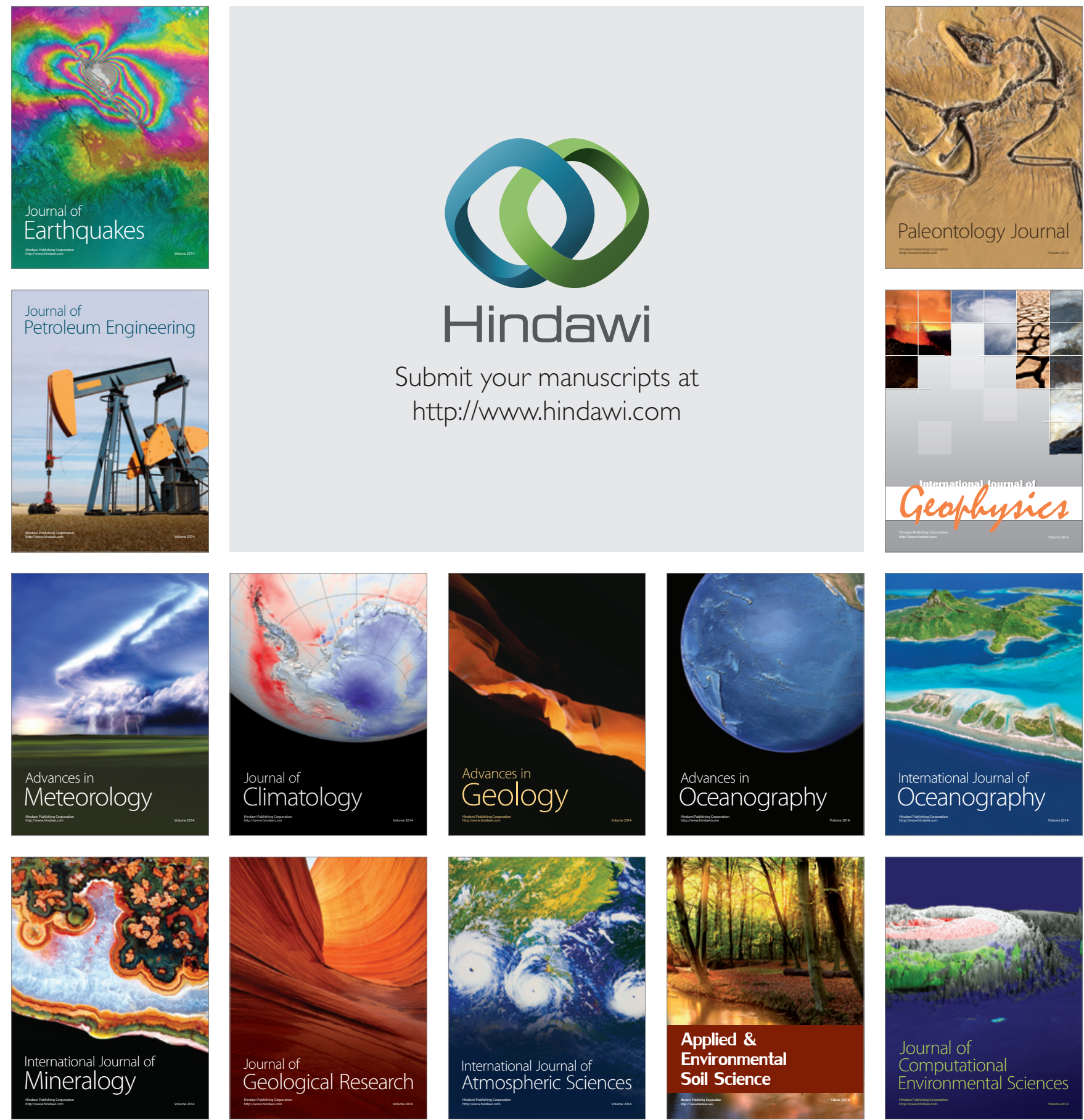